\title{
EMI Teacher Training at the University of A Coruña
}

\section{Crespo, Begoña ${ }^{a}$ and Llanos-Tojeiro, Ángela ${ }^{b}$}

${ }^{\mathrm{a}}$ Department of Letters, University of A Coruña, Spain, ${ }^{\mathrm{b}}$ Department of Letters, University of A Coruña, Spain.

\begin{abstract}
The aim of this paper is to offer an overview of how an EMI programme was designed at the University of A Coruña (Spain) to implement courses taught in English by its teaching staff. The final goals of this initiative were twofold: to attract an increasing number of foreign students through mobility or as new admissions; and to promote internationalisation at home for both students and lecturers. Some of the steps taken in this process (from coaching to EMI) are explained as well as the principles on which a particular teaching methodology for non-native speakers of English is based. Content knowledge and a B2 level of English is presupposed, but a further level of teacher professionalism is aspired to, involving commitment, reflection, responsibility. A shift in focus, from teacher-to student-centred learning is required. Instructors should show their students how to learn and guide them along their learning paths. This implies a shift in the original mindset that is strongly rooted in particular teaching traditions. Communicative competence is also a key factor: knowing how to transmit and communicate is at least as important as the material content itself, and lecturers should be good communicators.
\end{abstract}

Keywords: EMI; coaching protocol; teacher professional development; learner-centred teaching; communicative competence. 


\section{Introduction}

This paper focuses on some of the elements that should be taken into account in an EMI course, mainly within the context of a Spanish-speaking country, where teaching staff are not specifically trained to become university instructors. This is the case of the EMI teacher training implemented at the University of A Coruña (UDC, henceforth). This different approach to teaching in English offers the advantage of promoting new methodological commitments, such as making interactive and participatory lectures customary, and enforcing teaching strategies that can contribute to the success of teaching programs in English.

The paper is organized in this way: following an introduction to EMI and the specific context in which it is applied, section 2 will describe the UDC context and the pre-EMI coaching activities. Section 3 will be devoted to the EMI course and the three underpinning principles: teacher professional development, learner-centered teaching and instructors' communicative competence. Finally, some conclusions will be offered regarding the experience gained from the practical application of these principles.

\section{What is EMI? The UDC context}

As there exists wide confusion concerning some of the terminology currently used in this field of study within applied linguistics, we consider it most convenient to begin by clarifying what EMI is and how it differs from other possible denominations.

English as a Medium of Instruction (EMI) refers to the growing global phenomenon of the teaching of academic subjects through the medium of English in countries where the first language (L1) of the majority of the population is not English (Dearden, 2015) and where explicit language learning aims are not the priority of these classes (Madhavan \& McDonald, 2014).

Another acronym related to this terminological issue is CLIL (Content Language Integrated Learning). But CLIL "refers to situations where subjects, or parts of subjects, are taught through a foreign language with dual-focused aims, namely the learning of content, and the simultaneous learning of a foreign language (Marsh, 1994; 2000)". According to Smit and Dafouz (2012), in the university context the term CLIL has been altered to Integrating Content and Language in Higher Education (ICL or ICLHE) or English as a Medium of Instruction (EMI). Unlike CLIL at lower levels of education, where both language and content are the focus of learning, ICHLE and EMI teaching is devoted to course content, with the use of language as the medium of instruction (Morell, 2014). Different focuses seem to call for different denominations. 
For at least the last ten years, higher education institutions in non-English-speaking countries (Spain, Italy, Germany...) have been developing and implementing programmes for training teaching staff in what has become known as English as a Medium of Instruction (EMI).

The Universidade da Coruña (UDC) is one of the Spanish universities that decided in 2012 to launch, as part of its internationalisation policy, a training programme aimed at providing teachers with new linguistic and methodological habits, enabling them to teach courses forming part of bilingual or double degrees.

It was around this time that the CRUE (Spanish Rectors Association) decided to begin working on a document that could serve as a guide or orientation for Spanish universities wanting to implement bilingual programmes. Among many aspects, it was precisely the need to train university lecturers that was highlighted in the document (Bazo Martínez \&González Álvarez, 2017).

Within this framework UDC launched a tutorials planning effort that crystallized into a coaching programme.

\subsection{Pre-EMI: Coaching activities}

In 2013 the Vice-Chancellorship for internationalization made an agreement with the English Department to cooperate in the training of mainly STEM (Science, Technology, Engineering and Mathematics) lecturers. The initial stages involved coaching activities for those lecturers interested in teaching their courses in English. The primary tenet behind the iniciative was the belief that teachers should not be abandoned to intuition in working out the skills needed for teaching in English.

A coaching protocol was designed setting clear objectives and creating an honest and trustful relationship between coaches and coachees. In addition, this protocol was devised on the basis of the coachee's future potential, disregarding previous misconceptions of their performance. The coaches' aim was to motivate lecturers in their professional life and reengage them with teaching, especially by focusing on solutions rather than problems and by being optimistic and supportive. 
Activities were designed according to the following format:

\begin{tabular}{|l|l|}
\hline STAGES & GOALS \\
\hline 1. First contact & $\begin{array}{l}\text { Organise the calendar with input from the } \\
\text { parties involved. The teacher may provide } \\
\text { materials for revision. }\end{array}$ \\
\hline 2. Review of teaching materials & $\begin{array}{l}\text { Didactic materials, powerpoints and } \\
\text { Moodle pages are reviewed. Comments } \\
\text { from the coach. }\end{array}$ \\
\hline 3. Rehearsal and observation & $\begin{array}{l}\text { The coachee rehearses with the coach, who } \\
\text { observes, guides and supports. } \\
\text { The coach identifies strengths and } \\
\text { weaknesses and provides appropriate } \\
\text { strategies for minimizing the latter. }\end{array}$ \\
\hline 5. Classroom Observation & $\begin{array}{l}\text { The coach attends a class and later relays } \\
\text { observations to the coachee. }\end{array}$ \\
\hline orientation and linguistic support & $\begin{array}{l}\text { The coachee has at his/her disposal the } \\
\text { orientation and linguistic support of the } \\
\text { coach throughout the semester, up to a } \\
\text { maximum of 7 hours. } \\
\text { maximum of 7 hours. }\end{array}$ \\
\hline
\end{tabular}

To help structuralise this support program we designed file cards featuring the abovementioned activities for the coaches to maintain updated throughout the semester. The information collected would be used to prepare a guide for frequently asked questions, strategies, and helpful tips for the bilingual teacher. This card was filled in by all the coaches and the information they provided was commented on in regular meetings between coaches and coordinators throughout the semester.

In this coaching programme the idea was that the coach, linguistically speaking, acted as "a language teaching mentor", "an individual with recognized expertise comprising language 
teaching experience, knowledge, and skill. In a mentoring relationship with a language teacher, a mentor has more expertise than the teacher." (Sherris, 2010:1).

The classroom observation element was not well received by all lecturers. Successful teaching observations primarily form a part of the training process in order to create reflective and self-directed teacher-learners. While observations can be effective when undertaken as a collaborative and collegial exercise among peers, (Coe et al., 2014), as coaches we found, however, that they were not as effective as expected since coachees were reluctant to be observed.

\section{English as a Medium of Instruction course}

This programme was carried out according to the design and implementation of an EMI course made specifically for UDC instructors with a B2 level of English as described in the Common European Framework of Reference for Languages (CEFR). The EMI course was modelled on three fundamental pillars: teacher professional development, learner-centred teaching and lecturers' communicative competence.

\subsection{Teacher professional development}

The four dimensions of teacher professional development - knowledge, practice, reflection and engagement (Altrichter and Krainer, 1996) - take on a new meaning in the EMI course. University lecturers and instructors are now expected to master their content knowledge and teaching practice in English. Reflecting on their performance and engaging with their EMI peers will also help EMI instructors to keep improving.

Implementing and practicing learner-centred teaching, being familiar with different teaching techniques and strategies, and interacting with the learners help develop an effective teaching practice in English. EMI instructors must provide clear information about course objectives, learning outcomes, and evaluation, and give the students appropriate feedback. Active student participation should also be encouraged by asking different types of questions.

Last but not least are reflection and engagement. Thoughtful reflection on how to improve their teaching in English can help lecturers identify the most common weaknesses and the effective practices to overcome them. To reach this point, EMI lecturers can certainly benefit from a particular attitude: 'open-mindedness' concerning new ideas and thoughts, 'whole heartedness' and 'responsibility'. Among these, it is responsibility that clearly engenders engagement and participation with the professional community in pursuit of a life-long learning process with dedication to university education.

Achieving effective teaching through reflection and engagement and putting an emphasis on feedback, support, challenge, and professional learning may lead to improvement in 
student learning (Robert Coe, Cesare Aloisi, Steve Higgins and Lee Elliot Major October 2014: 10). This should be the obvious goal of a teaching professional.

\subsection{Learner-centred teaching}

The second pillar of EMI is the development of an attitude towards learner-centred teaching. Instilling this new attitude in the instructor is difficult for the trainer because it requires a change of mindset. The traditional teacher-centred lecture that figures so profoundly in the Spanish teaching culture has to be replaced by student-oriented teaching. This entails a transformation that becomes the greatest obstacle for EMI trainers.

Weimer (2002) identifies five areas in which teacher-centeredness in the classroom is clearly seen: the balance of power, the function of content, the role of the teacher, the responsibility of learning, and the purpose and processes of evaluation.

Weimer's thesis - that learner-centered teaching will lead to greater success for students and increased job satisfaction for teachers - has been supported in the pedagogical literature. Additionally, it has been recognized that the affective and cognitive domains interact to determine and favour classroom effectiveness.

Without a doubt, learner-centered teaching engages students in the process of learning more adequately. Learner-centered teachers provide students with essential skills to effectively master material in the discipline by showing them how to think, solve problems, evaluate evidence, analyse arguments, generate hypotheses. Allowing student participation in the process also encourages them as it promotes collaboration using the expertise of individual learners. All this active learning yields positive effects on motivation and engagement.

For UDC instructors, accustomed to a concept of educating in a teacher-centered scenario, this principle was the most controversial and difficult to assume. In fact, some widespread misconceptions surfaced about why a course taught in English might or might not be different from the same course taught in Spanish, with no regard to the added communicative difficulties of teaching in a language that is not one's native tongue. The resistance to modifying and adapting materials as a way to facilitate learning, focusing on the student as the main actor, is a challenge that remains to be met.

\subsection{Communicative Competence in EMI}

Communicative competence refers to the lecturer's ability to conduct a class in English and to convey information successfully. This does not refer to only what may be considered basic linguistic competence, but also embraces a sociocultural dimension that requires what is known as strategic competence, or "compensatory strategies in case of grammatical or sociolinguistic or discourse difficulties, such as the use of reference sources, grammatical and lexical paraphrase, requests for repetition, clarification, slower speech, or problems in 
addressing strangers when unsure of their social status or in finding the right cohesion devices." (Nordquist, 2018).

Consequently, communicative competence in EMI involves both verbal and nonverbal communication. Both have a lot to do with teacher performance.

Verbal communication encompasses the use of expressions to manage the classroom setting, that is, the use of specific classroom language: many different phrases can be used to organize presentations and to identify for the student what type of information is being presented. Some such phrases do the following: introduce a topic; give examples; emphasize main points; invite questions and support participation; and conclude a teaching session ("What we are going to cover today is . ..", "Now pay attention to this next part . . .", "So far (up until now), we have been discussing . . ., in the next class we will . .."). Other aspects, such as control of the lecturer's speaking volume and pace are also taken into account here. A loud voice (not too loud) shows confidence and implies authority. Speaking too softly may result in the student's failure to hearing important points. In addition, it is important in any learning environment to emphasize and repeat key concepts, which naturally involves slowing down the rate of speech in class, which is an especially sensitive issue faced by Spanish speakers of English.

Nonverbal communication conveys information about the lecturer's attitude toward the class and students, and it is a relevant component of the strategic dimension of communication. Making eye contact with the students to keep them engaged in the subject and attentive to what the lecturer has to say, the ability to monitor students' comprehension by observing their facial expressions, facing the students when talking to them, using gestures and facial expressions to clarify language and emphasize key ideas are complementary actions that improve communicative teaching performance.

In general, UDC lecturers that fail to apply interactivity in the classroom often neglect the communicative aspect of teaching. They may be responsible for conflating basic linguistic competence in an everyday English-speaking environment with the highly-specialized linguistic context of teaching. Being able to make oneself understood does not necessarily imply being able to help students learn.

\section{Final remarks}

Support for the linguistic and methodological development of lecturers teaching in English is part of the internationalization strategy of UDC (2014-2020). The model designed to this end evolved through different stages: from linguistic coaching and mentoring to structured courses devoted to the specific training of professionals. Teacher pofessional development is a key aspect for successful EMI, as in Spanish regulations research seems to take priority 
over teaching. In the particular case of UDC, difficulties were faced in attempting to convince lecturers of the benefits of learner-centred activities and interactive lectures. Equally challenging was the endeavor to change the traditional mindset of a decades-old learning environment, one that affected their own experiences as students.

All in all, both the coaching protocol and the EMI courses have helped many of the participants discover that enthusiasm and commitment open new possibilities for engaging students, which in the long run may translate into professional satisfaction.

\section{References}

Altrichter, H., \& Krainer, K. (1996). Wandel von Lehrerarbeit und Lehrerfortbildung. Lehrerfortbildung zwischen prozessen und produkten, 33-52.

Bazo Martínez, P. et al. (2017). Linguistic Policy for the Internationalisation of the Spanish University System: A framework document. http://www.crue.org/Documentos\%20compartidos/Sectoriales/Internacionalización\%20 y\%20Coorperación/Politica_Executive\%20summary_Version\%20Final\%20Reducido.p df

Brown, G. (2011). Student-Centered Learning in Higher Education. International Journal of Teaching and Learning in Higher Education, 23(3), 92-97.

Coe, R. et al. (2014). What makes great teaching? Review of the underpinning research. Durham University. https://www.suttontrust.com/wp-content/uploads/2014/10/Whatmakes-great-teaching-FINAL-4.11.14.pdf

Dearden, J. (2015). English as a medium of instruction: A growing global phenomenon. London: British Council.

Madhavan, D., \& Mcdonald, J. (2014). Food for thought. Webinar English as Medium of Instruction (EMI): Philosophies and Policies. Paris: OECD Higher Education Programme, 2014.

Marsh, D. (1994). Bilingual Education \& Content and Language Integrated Learning. International Association for Cross-cultural Communication, Language Teaching in the Member States of the European Union (Lingua). Paris: University of Sorbonne.

Marsh, D. (2000). An introduction to CLIL for parents and young people. In In D. Marsh \& G. Lange (Eds.), Using languages to learn and learning to use languages. Finland: University of Jyväskylä.

Morell, T. et al. (2014). English as the medium of instruction: a response to internationalization. Alicante: Universidad de Alicante. 
Nordquist, R. (2018). Communicative Competence Definition and Examples. ThoughtCo, Jan. 8, 2018, thoughtco.com/what-is-communicative-competence-1689768.

Smit, U., \& Dafouz, E. (eds.) (2012) Integrating Content and Language in Higher Education. AILA Review, 25. Amsterdam: John Benjamins.

Shaeiwitz, J.A., \& Turton, R. (2003). Educating chemical engineers in product design. International Journal of Engineering Education, 19, 153-157.

Sherris, A. (2010). Coaching Language Tearchers. CALdigest, 1-4. http://www.cal.org/siop/pdfs/digests/coaching-language-teachers.pdf

Weimer, M. (2002). Learner-centered teaching: Five key changes to practice. San Francisco: CA: Jossey-Bass. 